\title{
Circulating Neutrophil Extracellular Trap Levels in Well-Controlled Type 2 Diabetes and Pathway Involved in Their Formation Induced by High-Dose Glucose
}

\author{
Arina Miyoshi ${ }^{a}$ Mai Yamada ${ }^{c}$ Haruki Shida $^{a}$ Daigo Nakazawa $^{a}$ \\ Yoshihiro Kusunoki $^{\mathrm{a}}$ Akinobu Nakamura $^{\mathrm{a}}$ Hideaki Miyoshi $^{\mathrm{a}}$ Utano Tomaru $^{\mathrm{b}}$ \\ Tatsuya Atsumia Akihiro Ishizu ${ }^{d}$ \\ a Division of Rheumatology, Endocrinology and Nephrology and ${ }^{\mathrm{b}}$ Department of Pathology, Hokkaido University \\ Graduate School of Medicine, and ${ }^{\mathrm{C}}$ Graduate School of Health Sciences and d Faculty of Health Sciences, Hokkaido \\ University, Sapporo, Japan
}

\section{Key Words}

Aldose reductase inhibitor - Microvascular complications . Myeloperoxidase-DNA complex · Neutrophil extracellular trap Polyol pathway $\cdot$ Type 2 diabetes

\begin{abstract}
Objectives: Although intensive therapy for type 2 diabetes (T2D) prevents microvascular complications, $10 \%$ of wellcontrolled T2D patients develop microangiopathy. Therefore, the identification of risk markers for microvascular complications in well-controlled T2D patients is important. Recent studies have demonstrated that high-dose glucose induces neutrophil extracellular trap (NET) formation, which can be a risk for microvascular disorders. Thus, we attempted to determine the correlation of circulating NET levels with clinical/laboratory parameters in well-controlled T2D patients and to reveal the mechanism of NET formation induced by high-dose glucose. Methods: Circulating NET levels represented by myeloperoxidase (MPO)-DNA complexes in the serum of 11 well-controlled T2D patients and 13 healthy volunteers were determined by enzyme-linked im-
\end{abstract}

\begin{tabular}{|c|c|}
\hline KARGER & $\begin{array}{l}\text { (c) } 2016 \text { The Author(s) } \\
\text { Published by S. Karger AG, Basel } \\
1015-2008 / 16 / 0835-0243 \$ 39.50 / 0\end{array}$ \\
\hline www.karger.com/pat & $\begin{array}{l}\text { This article is licensed under the Creative Commons Attribution- } \\
\text { NonCommercial-NoDerivatives } 4.0 \text { International License (CC BY- } \\
\text { NC-ND) (http://www.karger.com/Services/OpenAccessLicense). } \\
\text { Usage and distribution for commercial purposes as well as any dis- } \\
\text { tribution of modified material requires written permission. }\end{array}$ \\
\hline
\end{tabular}

munosorbent assay. The pathway involved in the NET formation induced by high-dose glucose was determined using specific inhibitors. Results: Serum MPO-DNA complex levels were significantly higher in some well-controlled T2D patients in correlation with the clinical/laboratory parameters which have been regarded as risk markers for microvascular complications. The aldose reductase inhibitor, ranirestat, could inhibit the NET formation induced by high-dose glucose. Conclusions: Elevated levels of circulating NETs can be a risk marker for microvascular complications in well-controlled T2D patients. The polyol pathway is involved in the NET formation induced by high-dose glucose.

$$
\begin{aligned}
& \text { C } 2016 \text { The Author(s) } \\
& \text { Published by S. Karger AG, Basel }
\end{aligned}
$$

\section{Introduction}

Type 2 diabetes (T2D) is a growing health care burden primarily due to its long-term complications, including nephropathy, retinopathy, and neuropathy [1]. These complications are considered as microvascular disorders. 
In earlier studies, both abundant oxidative stress and nonenzymatic glycation of proteins associated with high levels of plasma glucose have been shown as risk factors for vascular endothelial cell damage in T2D [2].

Several clinical studies, including the Kumamoto study in Japan, have demonstrated that intensive therapy prevents the progression of microvascular complications in T2D [3-5]. However, approximately $10 \%$ of T2D patients in a well-controlled state still develop certain complications, such as nephropathy and retinopathy. Therefore, it is important to identify risk markers to predict the development of microvascular complications in wellcontrolled T2D patients.

Neutrophil extracellular traps (NETs) are net-like DNA decorated with antimicrobial proteins, including histones and myeloperoxidase (MPO), which are released from microorganism-triggered neutrophils [6]. The activated neutrophils die in due course with the formation of NETs. Consequently, the dying neutrophils can trap microorganisms by the net-like DNA and kill them using antimicrobial proteins. On the other hand, the histones that are NET components exhibit a strong cytotoxic effect on vascular endothelial cells [7] and exert thrombogenic activity in terms of the potential to bind platelets and coagulation factors in the blood $[8,9]$. Although the NET formation is regarded as an essential event in the innate immunity, excessive formation of NETs can induce vascular endothelial cell damage and thrombosis resulting in the development of microvascular disorders.

Recently, the glucose metabolism has been shown as a requirement for the NET formation [10]. In addition, it has been shown that the NET formation is increased under high-dose glucose condition and that the circulating NET levels in the serum are associated with T2D [11].

In the present study, in order to determine if the amount of NET formation in vivo can be a risk marker for microvascular complications in well-controlled T2D patients, we examined the relation of circulating NET levels represented by MPO-DNA complexes in the serum with certain clinical and laboratory parameters in these patients. We examined further the pathway involved in the NET formation induced by high-dose glucose.

\section{Methods}

Patients and Healthy Controls

Eleven patients diagnosed with T2D in the Hokkaido University Hospital were selected to be enrolled in this study because their casual plasma glucose (CPG) levels did not exceed $200 \mathrm{mg} /$ dl. Since all participants were outpatients, CPG was employed in this study instead of fasting plasma glucose. Clinical and laboratory parameters of these patients are shown in online supplementary table S1 (see www.karger.com/doi/10.1159/000444881 for all online suppl. material). Thirteen healthy volunteers were included in this study as controls. After obtaining written informed consent, peripheral blood samples $(5 \mathrm{ml})$ were obtained without anticoagulants, and the sera were stored at $-20^{\circ} \mathrm{C}$ until use. This study was approved for practice by the Institutional Clinical Research Committee of the Hokkaido University Hospital (permission No. 014-0043).

\section{Quantification of Circulating NETs}

The amount of in vivo NET formation can be monitored as MPO-DNA complexes in the serum [12]. The enzyme-linked immunosorbent assay (ELISA) for MPO-DNA complexes was carried out as described previously [12-14]. In brief, microtiter plates (Thermo Fisher Scientific, Waltham, Mass., USA) were first coated with the monoclonal antihuman MPO antibody (5 $\mu \mathrm{g} / \mathrm{ml}$; AbD Serotec, Kidlington, UK) and incubated overnight at $4^{\circ} \mathrm{C}$. After blocking with $1 \%$ bovine serum albumin, the sera (final dilution, 1:3) and horseradish peroxidase-conjugated anti-DNA antibody in the cell death detection kit (Roche Diagnostics, Tokyo, Japan) were applied to the wells followed by the development of color according to the manufacturer's instruction of the kit. The serum from a patient with MPO-antineutrophil cytoplasmic antibody-associated vasculitis served as a positive control.

\section{Reagents}

Reagents used in this study included phorbol myristate acetate (PMA; Sigma-Aldrich, St. Louis, Mo., USA), glucose (Wako Pure Chemical Industries, Osaka, Japan), mannitol (Wako Pure Chemical Industries), 2-deoxyglucose (2-DG; Wako Pure Chemical Industries), ranirestat (aldose reductase inhibitor; Sumitomo Dainippon Pharma, Sapporo, Japan), and sotrastaurin [protein kinase $\mathrm{C}(\mathrm{PKC})$ inhibitor; Sigma-Aldrich].

\section{Neutrophil Isolation and NET Induction}

Human neutrophils were obtained from $5 \mathrm{ml}$ of peripheral blood of healthy volunteers by density centrifugation using Polymorphprep (Axis-Shield, Dundee, UK) according to the manufacturer's instruction. The obtained cells were resuspended in RPMI1640 medium supplemented with $10 \%$ fetal bovine serum and then seeded in wells of 4-well chamber slides (Thermo Fisher Scientific, Yokohama, Japan) $\left(5 \times 10^{5} / \mathrm{ml}\right)$. After incubation for $15 \mathrm{~min}$ at $37^{\circ} \mathrm{C}$, the medium was removed, and then the remaining cells were washed with PBS. Thereafter, the remaining cells were exposed to $100 \mathrm{nM}$ PMA in PBS or to various concentrations of glucose in PBS for another $2 \mathrm{~h}$ at $37^{\circ} \mathrm{C}$ in order to induce NETs. Since conventional RPMI medium contains glucose at concentrations of $\sim 200$ $\mathrm{mg} / \mathrm{dl}$, we used PBS as solvent instead. After washing with PBS, the remaining cells were fixed with $4 \%$ paraformaldehyde for $15 \mathrm{~min}$ at room temperature, and then the chambers were removed. Finally, the remaining cells on the glass slides were incubated with the 4',6-diamidino-2-phenylindole (DAPI)-containing solution (Sigma-Aldrich).

\section{Quantification of NETs on Glass Slides}

Photomicrographs (magnification: $\times 200)$ were taken randomly under a fluorescent microscope (6/well of chamber slides). Si- 


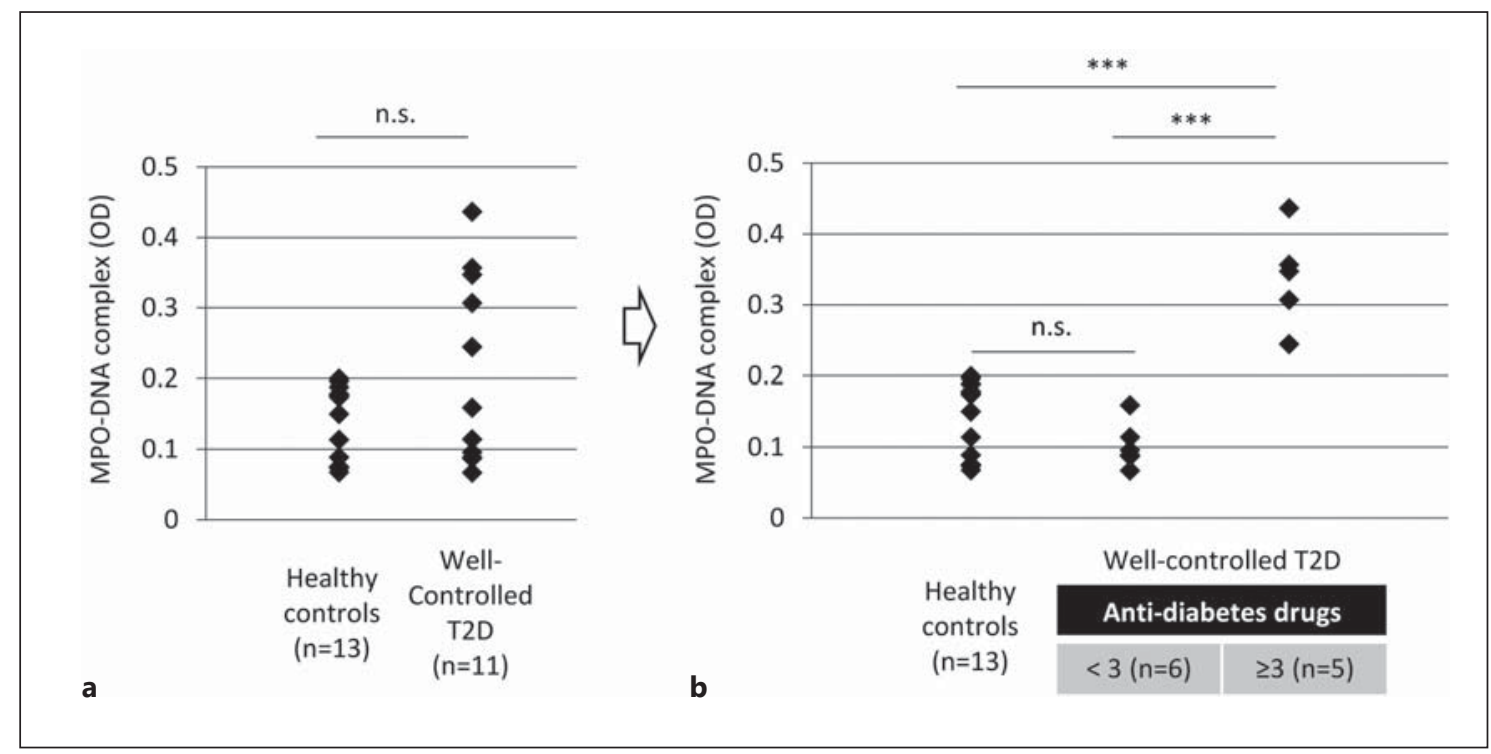

Fig. 1. Serum MPO-DNA complex levels. a Sera from healthy controls $(n=13)$ and well-controlled T2D patients $(\mathrm{n}=11)$ were subjected to ELISA. b The well-controlled T2D patients were divided into 2 subgroups: patients treated with $<3$ antidiabetic drugs $(n=6)$ and those treated with $\geq 3$ antidiabetic drugs $(n=5)$. n.s. $=$ Not significant. ${ }^{* * *} \mathrm{p}<0.001$.

multaneously, we observed the neutrophils that formed NETs under phase contrast condition in order to confirm cell death with rupture of the plasma membrane. The amount of NETs was determined as a mean value of DAPI-positive area/neutrophil of the 6 photomicrographs taken using ImageJ software as described previously [14].

\section{Statistics}

Two independent groups were compared using unpaired Student's t test. When the variance of the 2 groups was not equivalent, Welch's $t$ test was applied. $p$ values $<0.05$ were regarded as statistically significant.

\section{Results}

Serum MPO-DNA Complex Levels in Well-Controlled T2D Patients and Healthy Controls

In order to evaluate the NET formation in vivo, we determined the MPO-DNA complex levels in the sera of the well-controlled T2D patients $(n=11)$, and the data were compared with the healthy controls $(\mathrm{n}=13)$. As a result, the serum MPO-DNA complex levels were $0.209 \pm 0.133$ (mean optical density $\pm \mathrm{SD}$ ) in the well-controlled T2D patients and $0.135 \pm 0.053$ in the healthy controls (fig. 1a). Although the mean value of the T2D samples was higher than that of the healthy controls, they were not statisti- cally different. Since the T2D values showed greater variance than those of healthy controls, we next aimed to determine which factors were associated with a large variance. For this purpose, we focused on the quantity of antidiabetic drugs used in the T2D patients. Although the range of the HbAlc levels of the well-controlled T2D patients was relatively narrow [6.1-7.1\% $(43-53 \mathrm{mmol} /$ mol)] (online suppl. table S1), the type and quantity of antidiabetic drug used varied among individuals (online suppl. table S2). Thus, it is reasonable to consider that the patients who use more antidiabetic drugs are the ones with more severe T2D. Interestingly, when the well-controlled T2D patients were divided into 2 subgroups, namely, the patients treated with $<3$ antidiabetic drugs and those treated with $\geq 3$ antidiabetic drugs, the serum MPO-DNA complex levels in the latter subgroup $(n=5)$ were significantly higher than those in the former subgroup $(n=6)$ (fig. $1 b)$.

\section{Correlation of Serum MPO-DNA Complex Levels with Clinical and Laboratory Parameters of Well- Controlled T2D Patients and Healthy Controls}

Next, we examined the correlation of the serum MPODNA levels with certain clinical and laboratory parameters of the well-controlled T2D patients and healthy controls, including age, disease duration, body mass index 

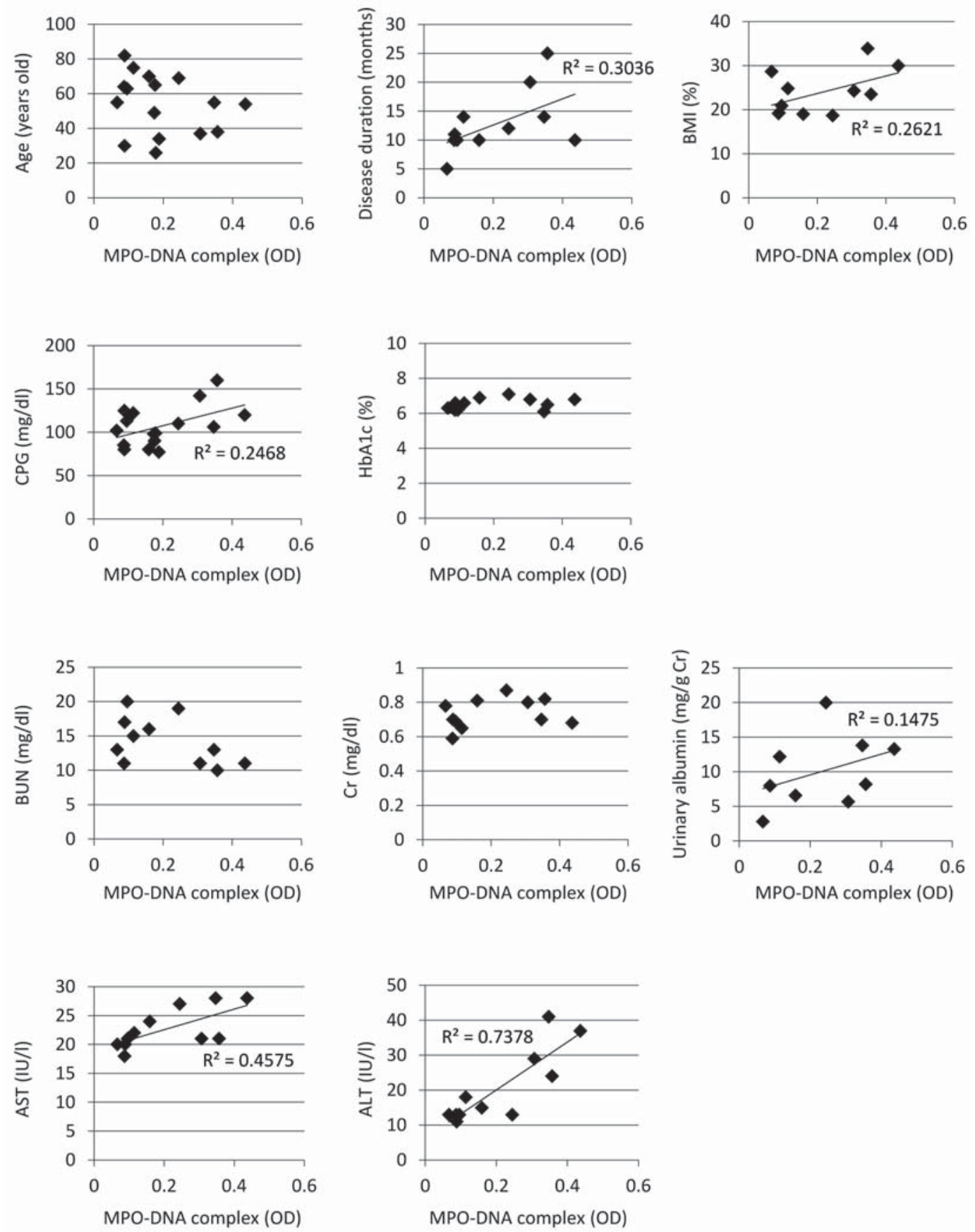

Fig. 2. Correlation of serum MPO-DNA complex levels with clinical and laboratory parameters of well-controlled T2D patients and healthy controls. The sample size is diverse per parameter according to the availability of data. $\mathrm{Cr}=$ Creatinine; $\mathrm{OD}=$ optical density. 


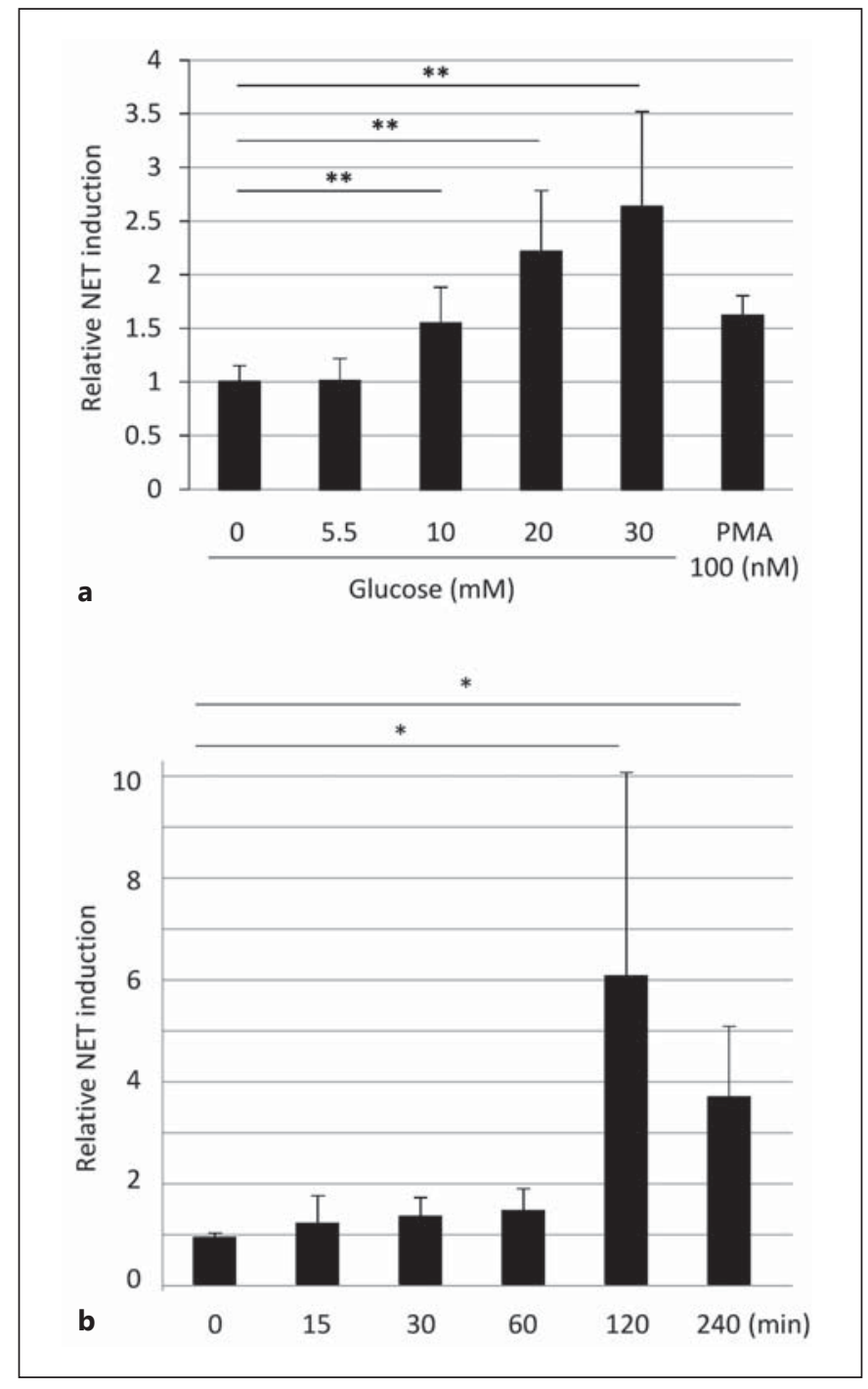

Fig. 3. NET induction by glucose. Experiments were repeated at least 3 times, and data were presented as means \pm SD. a Glucose dose dependency: neutrophils from healthy volunteers were exposed to various concentrations of glucose for $2 \mathrm{~h}$ at $37^{\circ} \mathrm{C}$ and then NET formation was quantified. The value when the neutrophils were incubated in PBS (0 mM glucose) was set as 1. PMA (100 nM in PBS) was employed as a positive control. ${ }^{* *} \mathrm{p}<0.01$. b Time dependency: neutrophils from healthy volunteers were exposed to $20 \mathrm{~mm}$ glucose for various durations at $37^{\circ} \mathrm{C}$, and then NET formation was quantified. The value before the neutrophils were incubated with glucose $(0 \mathrm{~min})$ was set as $1 .^{*} \mathrm{p}<0.05$.

(BMI), CPG, HbA1c, blood urea nitrogen, creatinine, urinary albumin, aspartate transaminase (AST), and alanine transaminase (ALT). Among them, disease duration, BMI, CPG, urinary albumin, AST, and ALT showed positive correlations $\left(\mathrm{r}^{2}>0.100\right)$ with the serum MPO-DNA complex levels (fig. 2). In order to elicit the strongest cor- relates with the serum MPO-DNA complex levels, logistic analysis was conducted. As a result, ALT was nominated as the strongest correlate with the serum MPODNA complex level $(\mathrm{p}<0.001)$.

\section{Dose- and Time-Dependent Induction of NETs by Glucose}

We next determined the mechanism of NET induction under high-dose glucose condition by in vitro experiments. At first, the dose dependency of glucose on the NET formation was examined. When the neutrophils from healthy volunteers were exposed to various concentrations of glucose for $2 \mathrm{~h}$ at $37^{\circ} \mathrm{C}$, the DAPI-positive area was significantly increased by the exposure to $>10 \mathrm{mM}$ of glucose, and the increase was dose dependent (fig. 3a). Next, the time dependency of NET induction by $20 \mathrm{mM}$ glucose was examined. As shown in figure $3 b$, NETs were initiated to be induced after incubation for $2 \mathrm{~h}$ under high-dose glucose condition.

\section{Requirement of Intracellular Glycometabolism on NET Induction by High-Dose Glucose}

Next, in order to rule out the possibility that the high osmotic pressure in the high-dose glucose solution affected the NET formation, we employed mannitol with osmotic pressure similar to glucose [15]. Since the exposure to $20 \mathrm{~mm}$ glucose, but not to mannitol, for $2 \mathrm{~h}$ at $37^{\circ} \mathrm{C}$ induced NETs (fig. 4a), NET induction under high-dose glucose was not caused by the high osmotic pressure. Moreover, in order to determine the requirement of intracellular metabolism of glucose on the NET formation under high-dose glucose condition, the glucose analogue, 2-DG, was employed. Glucose incorporated in neutrophils is phosphorylated to glucose-6-phosphate and becomes adenosine triphosphate. On the contrary, 2-DG is taken up by neutrophils via the glucose transporter, but it is not metabolized in the cells [16]. Interestingly, the exposure to $20 \mathrm{mM}$ glucose, but not 2-DG (even at $30 \mathrm{mM}$ ), for $2 \mathrm{~h}$ at $37^{\circ} \mathrm{C}$ induced NETs (fig. $4 \mathrm{~b}$ ). The collective findings suggest that the intracellular metabolism of glucose is essential for the NET induction under high-dose glucose condition.

\section{Involvement of the Polyol Pathway in NET Formation} Induced by High-Dose Glucose

The NET formation depends on the generation of reactive oxygen species (ROS) [17]. In the metabolism of glucose, the major pathway that generates ROS is the polyol pathway [18]. In this pathway, ROS are generated by NADH directly and by PKC that is activated by di- 

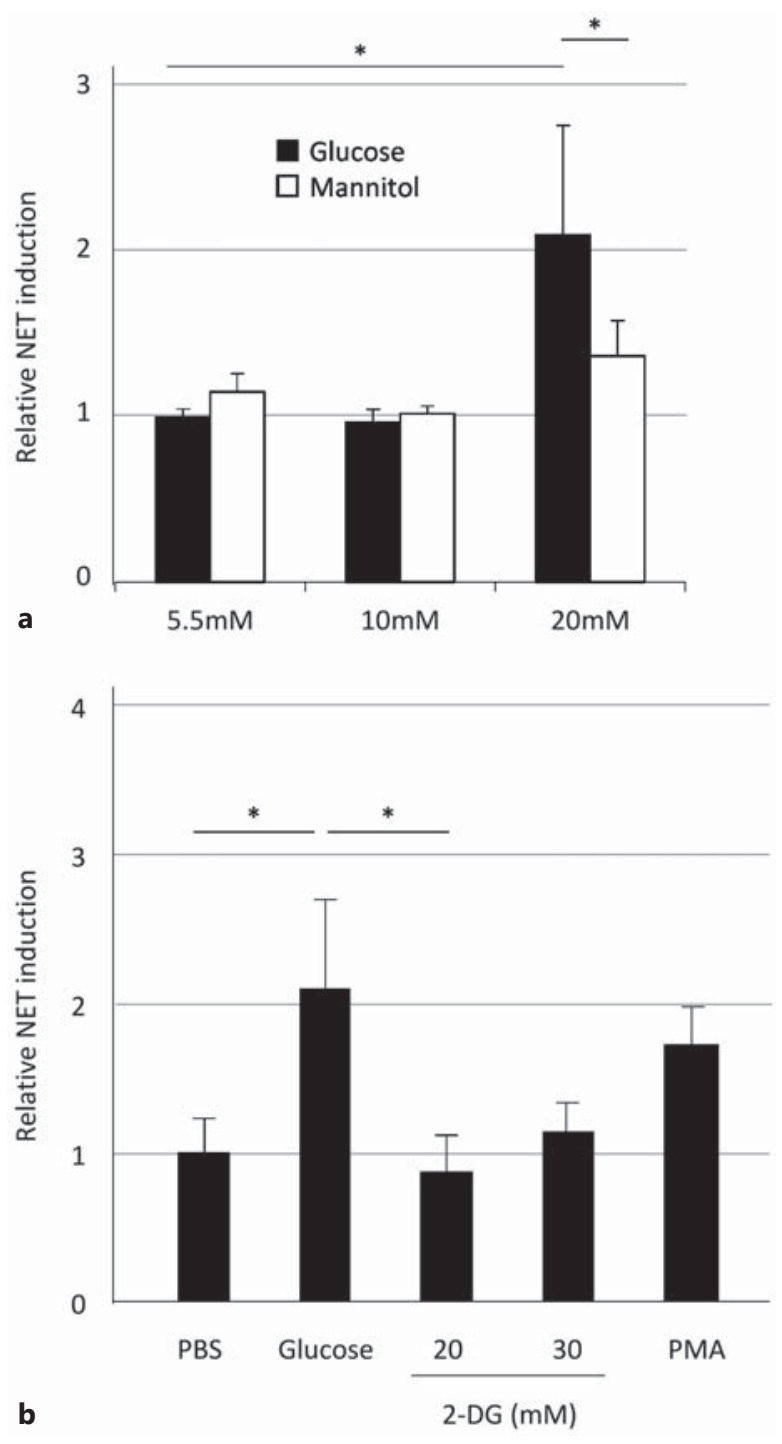

Fig. 4. Requirement of intracellular glycometabolism on NET induction by high-dose glucose. Experiments were repeated at least 3 times, and data were presented as means \pm SD. a Neutrophils from healthy volunteers were exposed to various concentrations of glucose or mannitol for $2 \mathrm{~h}$ at $37^{\circ} \mathrm{C}$, and then NET formation was quantified. The value when the neutrophils were incubated with $5.5 \mathrm{~mm}$ glucose was set as $1 .{ }^{*} \mathrm{p}<0.05$. $\mathbf{b}$ Neutrophils from healthy volunteers were exposed to $20 \mathrm{~mm}$ glucose or various concentrations of 2-DG for $2 \mathrm{~h}$ at $37^{\circ} \mathrm{C}$, and then NET formation was quantified. The value when the neutrophils were incubated in PBS (glucose, $0 \mathrm{mM}$ ) was set as 1 . PMA (100 nM in PBS) was employed as a positive control. ${ }^{*} \mathrm{p}<0.05$. acylglycerol, of which the production is mediated by $\mathrm{NADH}$ (online suppl. fig. S1). It has been shown that glucose challenge indeed induces ROS production in neutrophils [19] and that the polyol pathway in neutrophils is activated in patients with diabetic microvascular complications $[20,21]$.

In order to determine the involvement of the polyol pathway in the NET formation induced by high-dose glucose, we conducted experiments using specific inhibitors. Ranirestat was employed as an aldose reductase inhibitor that could function at the up- and mainstream of this pathway. Sotrastaurin was employed as a PKC inhibitor that could function downstream and at the tributary stream of the pathway. As a result, ranirestat inhibited completely the NET formation induced by high-dose glucose $(30 \mathrm{mM})$ even at low concentration $(0.25 \mu \mathrm{M})$ (fig. 5). In a like manner, sotrastaurin inhibited the NET formation, but the effect was partial even at high concentration $(1 \mu \mathrm{M})$. These findings suggest that the polyol pathway is involved in the NET formation induced by high-dose glucose, and the upstream inhibition is more effective than the downstream inhibition.

\section{Discussion}

More than 10 years have passed since the discovery of NETs in 2004 [6]. Up to now, many studies have revealed the biological roles of NETs. Although NETs are essential for the innate immunity, especially for the elimination of microbes, the extracellular release of DNA and intranuclear/cytoplasmic proteins is regarded as a risk factor for microvascular disorders [22]. Diverse stimuli, such as the bacterium-derived formyl-Met-Leu-Phe and lipopolysaccharide [23], PMA, antineutrophil cytoplasmic antibody [12, 14], and high-dose glucose [11], have been shown to induce NETs.

In the present study, we have demonstrated that the levels of circulating NETs represented by serum MPODNA complexes in the well-controlled T2D patients treated with several $(\geq 3)$ antidiabetic drugs are significantly higher than in the patients treated with less $(<3)$ antidiabetic drugs and healthy controls. Although further studies, for example continuous glucose monitoring, are needed, it is possible that the 'well-controlled' state is apparent in the patients treated with $\geq 3$ antidiabetic drugs, though their HbAlc value is equivalent to the patients treated with $<3$ antidiabetic drugs.

In addition, the serum MPO-DNA complex levels have positive correlations with some of the clinical and 
Fig. 5. Involvement of the polyol pathway in NET formation induced by high-dose glucose. Neutrophils from healthy volunteers were exposed to $30 \mathrm{~mm}$ glucose and diverse concentrations of ranirestat (aldose reductase inhibitor) or sotrastaurin (PKC inhibitor) for $3 \mathrm{~h}$ at $37^{\circ} \mathrm{C}$, and then NET formation was quantified. The value when the neutrophils were incubated in PBS (glucose, $0 \mathrm{mM}$; inhibitor, $0 \mu \mathrm{M}$ ) was set as 1. Experiments were repeated at least 3 times, and data were presented as means \pm SD. ${ }^{*} \mathrm{p}<0.05,{ }^{* *} \mathrm{p}<0.01$.

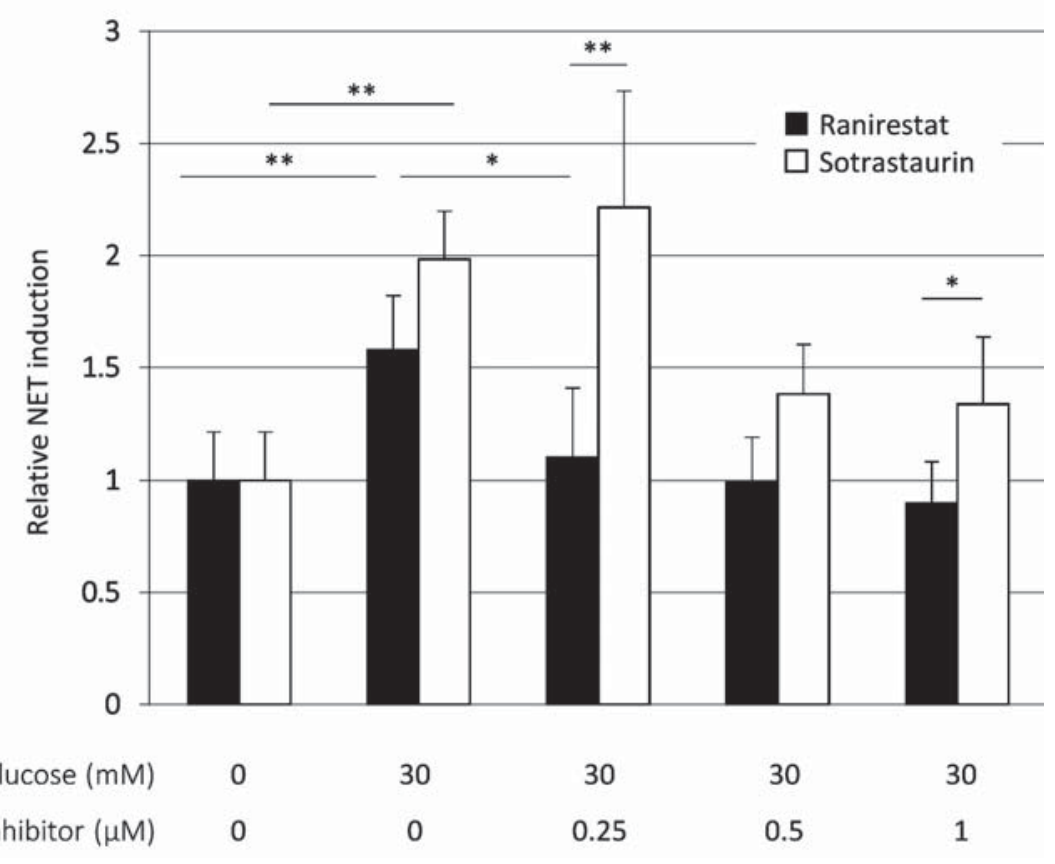

laboratory parameters of the well-controlled T2D patients. These parameters, including prolonged disease duration, and high levels of BMI, CPG, urinary albumin, AST, and ALT, are known risk factors for the cardiovascular complications of T2D [24]. Therefore, we suggest that the amount of NET formation in vivo can be a risk marker for microvascular complications in the well-controlled T2D patients. The logistic analysis suggests ALT as the strongest correlate with the serum MPO-DNA complex level. Liver enzymes, especially ALT, are shown to be predictors for incident diabetes [25]. Thus, the strong correlation of serum MPO-DNA complex levels with ALT values suggests that these markers can disclose the 'not good' control of the apparently 'well-controlled' T2D patients.

The NET formation in the T2D patients is fraught with controversies. Joshi et al. [26] first demonstrated that the potential of NET formation induced by lipopolysaccharides and PMA in neutrophils derived from T2D patients was lower compared with healthy controls and suggested that it could link to their susceptibility to infection. On the contrary, Menegazzo et al. [11] showed that high-dose glucose and hyperglycemia increased the release of NETs. In the present study, we have demonstrated that serum MPO-DNA complex levels are elevated in some patients with well-controlled T2D. On the other hand, neutrophils derived from T2D patients formed fewer NETs under high-glucose condition than those from healthy donors [our unpubl. observations]. These findings suggest that incidental hyperglycemia, e.g. postprandial hyperglycemia, can induce NET formation in vivo under well-controlled conditions in T2D patients because the potential of NET formation persists in such situations. This hypothesis is consistent with previous reports, which demonstrated that acute glucose fluctuations rather than sustained chronic hyperglycemia activated oxidative stress and, thus, were associated with the development of microvascular complications in T2D patients $[27,28]$.

The limitations of this study are its retrospective study design and small sample size $(n=24)$ from a single institution. Further investigations with enrollment of more participants from multiple institutions are needed to confirm the correlation of the amount of NETs in vivo with certain clinical and laboratory parameters in well-controlled T2D patients. In addition, prospective studies investigating differences in the outcome of well-controlled T2D patients with high and low levels of circulating NETs should be conducted in the future.

The identification of the pathway involved in the NET formation induced by high-dose glucose is worthy of at- 
tention. The latest study has demonstrated that the increase in the NET formation in T2D is associated not only with microvascular complications but also with impaired wound healing $[29,30]$. The blockade of the polyol pathway, especially upstream events, can completely inhibit the NET formation induced by high-dose glucose. In fact, the aldose reductase inhibitor, ranirestat, has completed two phase III clinical trials and exhibited reproducible results of measurable objective beneficial effects on diabetic neuropathy $[31,32]$. In addition, it has been shown that in the polyol pathway aldose reductase plays a pathogenic role in the development of other cardiovascular complications of T2D as well as neuropathy [33]. Inhibition of aldose reductase activity is, therefore, a useful strategy for the prevention and treatment of cardiovascu- lar complications arising from $\mathrm{T} 2 \mathrm{D}$. We suggest that a part of the efficiency of aldose reductase inhibitors such as ranirestat is attributable to the inhibitory effect on the NET induction.

\section{Acknowledgment}

This study was supported by a grant-in-aid (No. 15K15105) from the Ministry of Education, Culture, Sports, Science and Technology of Japan to A.I.

\section{Disclosure Statement}

The authors have no conflicts of interest to report.

\section{References}

1 Liebl A, Khunti K, Orozco-Beltran D, Yale JH: Health economic evaluation of type 2 diabetes mellitus: a clinical practice focused review. Clin Med Insights Endocrinol Diabetes 2015; 8:13-19.

2 Roberts AC, Porter KE: Cellular and molecular mechanisms of endothelial dysfunction in diabetes. Diab Vasc Dis Res 2013;10:472-482.

3 Ohkubo Y, Kishikawa H, Araki E, Miyata T, Isami S, Motoyoshi S, Kojima Y, Furuyoshi N, Shichiri M: Intensive insulin therapy prevents the progression of diabetic microvascular complications in Japanese patients with non-insulin-dependent diabetes mellitus: a randomized prospective 6-year study. Diabetes Res Clin Pract 1995;28:103-117.

4 Turner RC, Holman RR: Lessons from UK prospective diabetes study. Diabetes Res Clin Pract 1995;28(suppl):S151-S157.

5 Kohner EM: Microvascular disease: what does the UKPDS tell us about diabetic retinopathy? Diabet Med 2008;25(suppl 2):2024.

6 Brinkmann V, Reichard U, Goosmann C, Fauler B, Uhlemann Y, Weiss DS, Weinrauch Y, Zychlinsky A: Neutrophil extracellular traps kill bacteria. Science 2004;303:15321535.

$7 \mathrm{Xu}$ J, Zhang X, Pelayo R, Monestier M, Ammollo CT, Semeraro F, Taylor FB, Esmon NL, Lupu F, Esmon CT: Extracellular histones are major mediators of death in sepsis. Nat Med 2009;15:1318-1321.

8 Fuchs TA, Brill A, Duerschmied D, Schatzberg D, Monestier M, Myers DD Jr, Wrobleski SK, Wakefield TW, Hartwig JH, Wagner DD: Extracellular DNA traps promote thrombosis. Proc Natl Acad Sci USA 2010;107: 15880-15885.
9 Fuchs TA, Brill A, Wagner DD: Neutrophil extracellular trap (NET) impact on deep vein thrombosis. Arterioscler Thromb Vasc Biol 2012;32:1777-1783.

10 Rodriguez-Espinosa O, Rojas-Espinosa O, Moreno-Altamirano MM, Lopez-Villegas EO, Sanchez-Garcia FJ: Metabolic requirements for neutrophil extracellular traps formation. Immunology 2015;145:213-224.

11 Menegazzo L, Ciciliot S, Poncina N, Mazzucato M, Persano M, Bonora B, Albiero M, Vigili de Kreutzenberg S, Avogaro A, Fadini GP: NETosis is induced by high glucose and associated with type 2 diabetes. Acta Diabetol 2015;52:497-503.

12 Kessenbrock K, Krumbholz M, Schonermarck U, Back W, Gross WL, Werb Z, Grone HJ, Brinkmann V, Jenne DE: Netting neutrophils in autoimmune small-vessel vasculitis. Nat Med 2009; 15:623-625.

13 Nakazawa D, Tomaru U, Suzuki A, Masuda S, Hasegawa R, Kobayashi T, Nishio S, Kasahara M, Ishizu A: Abnormal conformation and impaired degradation of propylthiouracil-induced neutrophil extracellular traps: implications of disordered neutrophil extracellular traps in a rat model of myeloperoxidase antineutrophil cytoplasmic antibody-associated vasculitis. Arthritis Rheum 2012;64:37793787.

14 Nakazawa D, Shida H, Tomaru U, Yoshida M, Nishio S, Atsumi T, Ishizu A: Enhanced formation and disordered regulation of NETs in myeloperoxidase-ANCA-associated microscopic polyangiitis. J Am Soc Nephrol 2014; 25:990-997.
15 Chen FQ, Wang QY, Wei GZ, Ma XY, Ma DW, Deng WW, Sun WB: Effects of mycophenolate mofetil on the expression of monocyte chemoattractant protein-1 and fibronectin in high glucose cultured human mesangial cells. Genet Mol Res 2014;13:3154-3161.

16 Marcus RG, England R, Nguyen K, Charron MJ, Briggs JP, Brosius FC 3rd: Altered renal expression of the insulin-responsive glucose transporter GLUT4 in experimental diabetes mellitus. Am J Physiol 1994;267:F816-F824.

17 Kirchner T, Moller S, Klinger M, Solbach W, Laskay T, Behnen M: The impact of various reactive oxygen species on the formation of neutrophil extracellular traps. Mediators Inflamm 2012;2012:849136.

18 Koya D, King GL: Protein kinase $C$ activation and the development of diabetic complications. Diabetes 1998;47:859-866.

19 Mohanty P, Hamouda W, Garg R, Aljada A, Ghanim H, Dandona P: Glucose challenge stimulates reactive oxygen species (ROS) generation by leukocytes. J Clin Endocrinol Metab 2000;85:2970-2973.

20 Dent MT, Veves A, Tebbs SE, Gonzalez AM, Malik RA, Boulton AJ, Ward JD, Wilson RM: Neutrophil aldose reductase activity as a potential marker for neuropathy and cataract in diabetes. Diabet Med 1991;8:911-916.

21 Dent MT, Tebbs SE, Gonzalez AM, Ward JD, Wilson RM: Neutrophil aldose reductase activity and its association with established diabetic microvascular complications. Diabet Med 1991;8:439-442.

22 Doring Y, Weber C, Soehnlein O: Footprints of neutrophil extracellular traps as predictors of cardiovascular risk. Arterioscler Thromb Vasc Biol 2013;33:1735-1736. 
23 Remijsen Q, Kuijpers TW, Wirawan E, Lippens S, Vandenabeele P, Vanden Berghe T: Dying for a cause: NETosis, mechanisms behind an antimicrobial cell death modality. Cell Death Differ 2011;18:581-588.

24 Pandey A, Chawla S, Guchhait P: Type-2 diabetes: current understanding and future perspectives. IUBMB Life 2015;67:506-513.

25 Doi Y, Kubo M, Yonemoto K, Nimomiya T, Iwase M, Tanizaki Y, Shikata K, Iida M, Kiyohata Y: Liver enzymes as a predictor for incident diabetes in a Japanese population: the Hisayama study. Obesity 2007;15:1841-1850.

26 Joshi MB, Lad A, Bharath Prasad AS, Balakrishnan A, Ramachandra L, Satyamoorthy K: High glucose modulates IL-6 mediated immune homeostasis through impeding neutrophil extracellular trap formation. FEBS Lett 2013;587:2241-2246.
27 Monnier L, Mas E, Ginet C, Michel F, Villon L, Cristol JP, Colette C: Activation of oxidative stress by acute glucose fluctuations compared with sustained chronic hyperglycemia in patients with type 2 diabetes. JAMA 2006; 295:1681-1687.

28 Xu F, Zhao L, Su J, Chen T, Wang X, Chen J, Wu G, Jin Y, Wong X: The relationship between glycemic variability and diabetic peripheral neuropathy in type 2 diabetes with well-controlled HbA1c. Diabetol Metab Syndr 2014;6:139.

29 Wong SL, Demers M, Martinod K, Gallant M, Wang Y, Goldfine AB, Kahn CR, Wagner DD: Diabetes primes neutrophils to undergo NETosis, which impairs wound healing. Nat Med 2015;21:815-819.
30 Fadini GP, Menegazzo L, Rigato M, Scattolini V, Poncina N, Bruttocao A, Ciciliot S, Mammano F, Ciubotaru CD, Brocco E, Marescotti MC, Cappellari R, Arrigoni G, Millioni R, Vigili de Kreutzenberg S, Albiero M, Avogaro A: NETosis delays diabetic wound healing in mice and humans. Diabetes 2016, Epub ahead of print.

31 Bril V, Hirose T, Tomioka S, Buchanan R: Ranirestat for the management of diabetic sensorimotor polyneuropathy. Diabetes Care 2009;32:1256-1260.

32 Giannoukakis N: Evaluation of ranirestat for the treatment of diabetic neuropathy. Expert Opin Drug Metab Toxicol 2014;10:10511059.

33 Cogan DG, Kinoshita JH, Kador PF, Robison G, Datilis MB, Cobo LM, Kupfer C: NIH conference. Aldose reductase and complications of diabetes. Ann Intern Med 1984;101:82-91. 